\title{
Managing marriage in contemporary China: Parenthood in precarious times
}

Edition 3, 2020

Sarah Gosper

DOI: 10.37839/MAR2652-550X3.2

On a crisp Sunday morning in the Chinese city of Xi'an, matchmaker Wang sets up her wares for the first time since the COVID-19 lockdown was lifted two months ago.

She opens her fold-up table, placing several plastic folders on it, a notepad and a jar of steaming jasmine tea and sits down on one of three stools. Her husband potters about behind her, slowly hanging up a string of red laminated posters and positioning a large white board with a long list of names divided by sex and age.

The matchmaking corner at Revolution Park is well known to locals across Xi'an. The 'market' is held every Wednesday and Sunday and it is a site devoted to matching unmarried women and men.

While not expecting many customers, Wang is surprised by the end of the day at how many parents came seeking her matchmaking services. It seems nothing much has changed since the outbreak of COVID-19. Parents in their fifties and sixties have returned to continue their conversations and complaints about their children's unwillingness to marry.

Matchmakers such as Wang listen, debate, and attempt to solve these parents' woes. Despite participating in often lengthy discussions, matchmakers are disliked and distrusted as profit-seekers and tricksters. Few parents admit that they actually believe in this method of matchmaking and the success rate is incredibly low. 
Parents seemingly attend the park because they see it as a way of fulfilling their duty, and also possibly because it is an opportunity to voice and discuss their dissatisfactions - about their unmarried children, what they see as the excessive demands of other parents, untrustworthy matchmakers, and what many perceive as a 'crisis' of marriage in China.

For the older generation, marriage is still considered the bedrock of Chinese society. But younger people are increasingly deferring marriage and more marriages are ending in divorce, which is a worrying and incomprehensible trend for many of China's older generation. Over the past decade, marriage rates have been steadily dropping, from 9.9 couples per 1,000 people in 2013, to 7.2 in 2018. Moreover, divorce rates are rapidly increasing. In 2016, 4.2 million couples filed for divorce, an increase of 8.3 percent from the previous year. In comparison to other nations however, China's marriage rate continues to sit among the highest in the world. In Australia, Taiwan, and Sweden, for example, the marriage rate sits at 4.8, 6, and 5 couples per 1,000 people, respectively.

The notion of a marriage 'crisis' reflects a widespread cultural belief and political concept that marriage is the bedrock of a stable and solid society. However, many young people in China do not share their parents' views on the importance of marriage. Instead, they consider marriage a huge risk that requires enormous financial outlay and perpetuates unequal gender roles.

\section{Matchmaking at Revolution Park}

The matchmaking corner in Xi'an is not as extensive as those in Shanghai or Beijing, spanning a space only the size of a basketball court, but it has operated for over a decade. It is divided into sections according to a variety of demographics such as the widowed, divorced, or never-married over fifty; as well as young post doctorates, migrant workers, ethnic minorities, singles working outside of Xi'an, and rural residents. 
The core section of the matchmaking corner is always humming with activity and energy. Scores of parents in their fifties and sixties can be heard chanting the same questions over and over, "son or daughter?", "what year?", "how tall?". This highly competitive atmosphere connects parents to one key goal: securing a daughter or son-in-law.

Young faces are a rarity at the Xi'an matchmaking corner. It is stereotyped as a distinctly uncool place where only 'overage' (daling - an unmarried person over 30) singles and their parents hang out. Most young women and men are embarrassed by the matchmaking corners and loathe the interference of their parents in their personal lives. Others highlight how unnatural the process is, complaining that blind dates are 'old fashioned', and pointing out the potentially uncomfortable and awkward nature of such an encounter.

The key feature of the matchmaking corner is the thousands of posters that are strung up between tree trunks, stapled to bushes, and stuck on tree branches. Some of them are typed and laminated, but many are handwritten, on plain sheets of paper. On these posters are the personal details of an unmarried woman or man: year of birth, height, weight, marital status (never married; briefly married; divorced; or widowed), education, hukou (household registration), employment, and parent's working status (retired or not retired). For men, additional points outline house and car ownership as well as income level; and for women, references are made to her physical attributes and modest demeanour. Underneath this personal description is a basic outline of a desired partner.

These posters are either written by a matchmaker or a parent, and most young people are unaware that their parents are advertising their availability for marriage. The phone number at the bottom of the poster usually belongs to either a matchmaker or the mother of the singleton on display. There is very little variety between the posters and it is rare to see one with a photograph. 


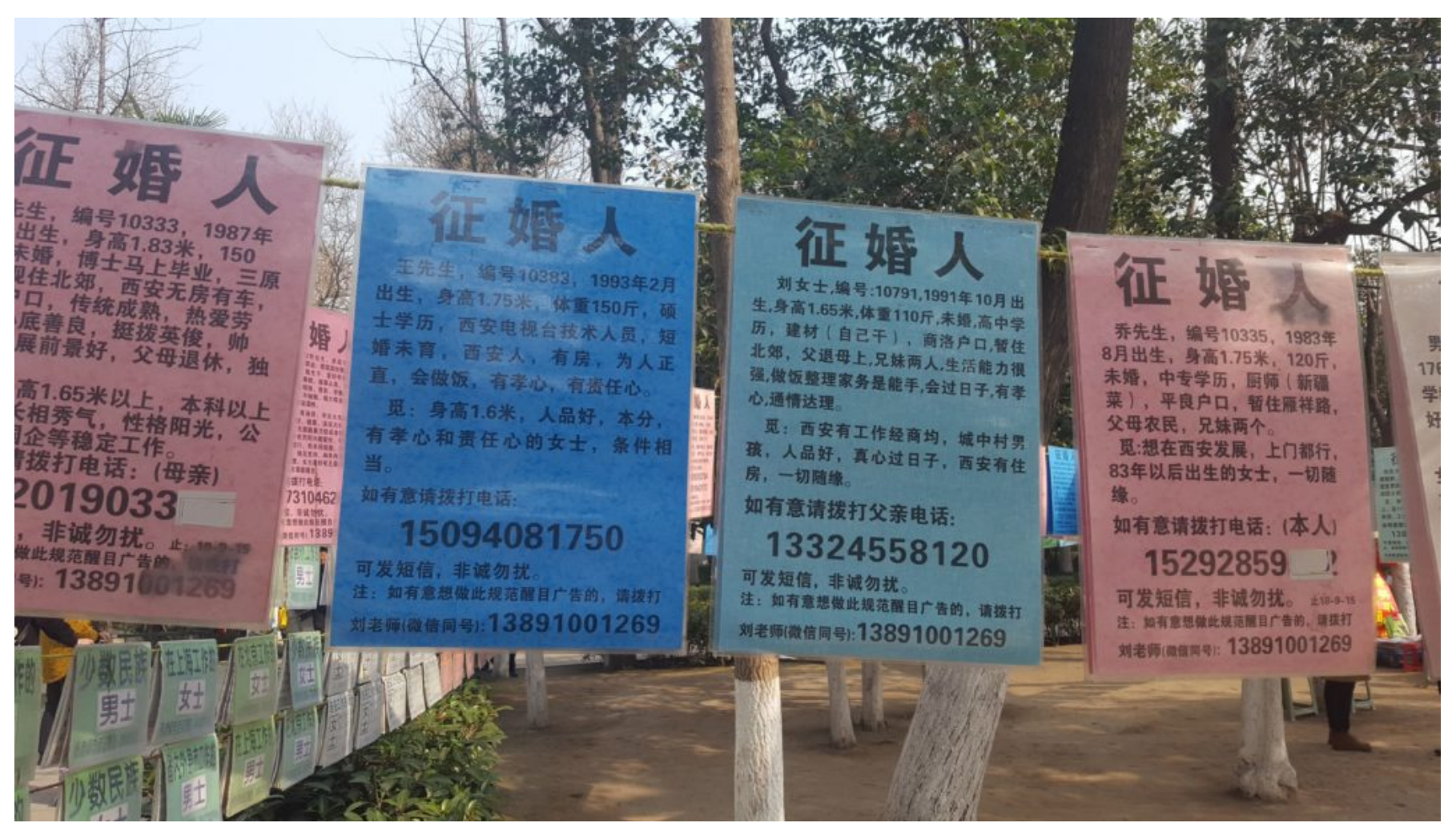

\section{Unrealistic expectations and fake profiles}

There are thousands of posters in the Xi'an matchmaking corner, too many in fact for each one to be read. Some parents described this line-up as akin to a Xi'an 'city bulletin board', remarking on the sheer amount of 'choice' available to parents.

Upon inspecting the posters, parents regularly chide each other for their 'excessive' (guofen) demands in a daughter or son-in-law. Prerequisites listed in the posters generally emphasise characteristics such as minimum height, income and education, to the exclusion of all those who do not qualify. On one visit to the park, the mother of a 24-year-old woman complained to me that her daughter, a technical college graduate, did not meet the minimum undergraduate requirements stated in most posters. Moreover, standing at over 1.7 metres, she was far too tall for the desired height category of 1.6-1.65 metres. This tendency to point out the supposedly unrealistic demands of other parents was widespread. By emphasising the irrational and unfair demands of some, parents are able to deflect responsibility away from 
their child's perceived shortcomings, to the marriage market as a whole.

There is also a sense of distrust on the part of attendees towards the posters on display. "The information in these posters is all fake" exclaimed Mr Chan, a fortyyear old unmarried man, "they write a younger age on the poster and then when you meet them you realise just looking at them that they are much older." Mr Chan was not the only person who questioned the genuineness of the information in the posters. Many were alert to the possibility of deception, wary of false claims over age or even marital status. Another frequent visitor to the park, the elderly father of an unmarried woman in her early thirties, decried the tactics of parents who try to disguise the stigma of divorce by describing their child's marital status as 'briefly married', instead of 'divorced'.

\section{Publicly performing virtuous parenthood}

"I am his father, I need to come. Parents care the most about this issue for their children. If parents do not care, who will?". This statement was uttered by Mr Ye, who is very concerned about his 45-year-old never-married son. Mr Ye has been attending the matchmaking corner for years. He arrives early in the morning and dutifully scans the vast array of posters in the hope of finding someone suitable. Over the years he has found a few possible matches, but says his son is never satisfied. He once found a very promising match, and says his son talked to this woman for more than two months. Eventually however, he decided that he was not interested in pursuing a relationship with her and so Mr Ye restarted his weekly trips to the matchmaking corner. Despite this setback, he explained that it is his duty as a parent to take on this matter on his son's behalf and he was committed to the quest until the situation had been resolved. I heard comments like this from parents every time I visited the matchmaking corner. There is a deep sense of duty among many parents who frequent the corner and their visits to the park are often framed in this rhetoric of noble parental duty.

In many ways, the matchmaking corner is a place of public performance of 'good 
parenting' and is an extension of the dedication parents have exhibited throughout their child's life. At matchmaker tables, parents enjoyed telling others how important their role was in 'helping' their child find a suitable partner and how much their children appreciated their matchmaking assistance. In this sense, the matchmaking corner functions as a forum for parents who feel the need to display their dedication to their children and their parental duties.

\section{Collectively raging against modern times}

One afternoon I found myself sitting with matchmaker Zhang and the mother of an unmarried 32-year-old man, discussing, what she believed to be, the problem with marriage in China today: women and education. Women are often blamed for what many see as their excessive expectations of a future husband, generally considered to have arisen a consequence of women's higher educational achievements. This type of debate is a hot topic of conversation among many parents who frequent the matchmaking corner. Whilst matchmaker Zhang and I were talking to this woman, a small crowd gathered around us. As the crowd grew in numbers, the woman's tone of voice changed, her mannerisms grew more exaggerated, and her language more evocative. The people huddled around us became increasingly animated, nodding their heads furiously and shouting in agreement. Matchmaker Zhang interjected multiple times to voice his support, garnering a wave of appreciative glances from the parents standing around us. This debate clearly unites these parents, particularly those with sons.

Rapid economic and social changes in China have resulted in a particularly pronounced generation gap. The post-80s generation (balinghou) are the besteducated, highest-earning, and most individually ambitious generation in China. They have far greater choice available to them due to steady economic growth and a growing consumer culture. This has subsequently influenced how young people define marriage and what they are looking for in a partner. Unlike their parents whose main focus is household stability and the continuation of the family line, young people are searching for a fulfilling relationship, particularly emphasising 
criteria such as emotional intimacy and intellectual stimulation.

These values, as well as the fast-paced environment that young people live in today is vastly different to the harsh, Maoist world that their parents grew up in. Having endured years of hardship, many parents are eager for their children to pursue a life - a marriage and career - that is underpinned by stability and wealth. This desire becomes even more pertinent considering the impact on parents of the former onechild policy. Having dismantled traditional family structures, urban parents subsequently channelled their entire resources into the development of their one child. For many this became an opportunity to empower their daughters to reject traditional and unequal gender expectations in marriage.

The impact of these changes for the older generation is both real and perceived. The relative elevation in women's status has rattled the local marriage market, but enduring patriarchal norms undermine both women's and men's future hopes and marital desires. There is a genuine disconnect between the young and the old in China, and the misunderstandings around marriage and partner selection criteria fuel this sense of 'crisis'.

A seat at a matchmaker's table is a chance to vent the sense of precarity gripping many parents. During one of my trips to the matchmaking corner, I was sitting with matchmaker Wang when a woman stopped by her table looking on behalf of her son, a recently-divorced taxi driver aged 33. She sat with us for more than half-an-hour (pushing the stroller of one of her grandchildren back and forth) as she explained her son's situation. He had been married for only two years, when his wife divorced him. To make matters worse, no child had been born out of the relationship. The sadness she felt about her son's situation was visceral, but even more so the fury directed at her former daughter-in-law. The likelihood of her divorced son remarrying was at the forefront of the conversation, yet there was little reassurance matchmaker Wang could provide. We all knew that, for a divorcee, re-marriage would be tough. When the conversation ended, and she eventually stood up to leave, there had been no transaction made, no fee paid to have her son advertised on a 
poster or listed in matchmaker Wang's book. The sole purpose of this conversation seemed to be to seek comfort for and to vent rage at the dissolution of her son's marriage.

Outdoor public parks have always been a place of camaraderie for older Chinese and matchmaking spaces in particular are ones where they can debate these changes with a sense of place and belonging. The matchmaking corner is an opportunity to vent these frustrations with other like-minded individuals, ultimately offering parents a degree of consolation and a reminder that their views are not held in isolation. In this way, it is a manifestation of a public outpouring of emotion in reaction to the rapid changes occurring in contemporary Chinese society.

\section{Matchmakers: easy listeners}

Matchmakers play a pivotal role at the matchmaking corner. There are about 20 of them scattered across the park set up with tables and stools. The majority of matchmakers are, like their clientele, retirees. For a small fee of 50RMB up to 400RMB (approx. 10AUD to 80AUD), a parent can be given a potential suitor's name and phone number or have their child's name listed in a book of singles for up to one year. For a higher price, they can have a poster drawn up and hung in that matchmaker's quarters.

However, matchmakers also provide an opportunity for parents to brag about their children in a social context that otherwise would not warrant boasting. The fact that their child is not yet married is a sore point - a point of failed parenting almost. However, many parents have a willing audience in matchmakers and other visitors to the park, and they use this opportunity and the guise of matchmaking to praise their child's achievements. I was regularly privy to conversations that highlighted the myriad skills of young women working as high-school teachers, or university professors, and young men with high-ranking positions in the military or government. In these moments, the conversation would also include other parents who would compete to highlight their favourable family background and their 


\section{MELBOURNE ASIA REVIEW}

July 13,2020

daughter or son's accomplishments. Their expectations in a daughter or son-in-law often mirrored these hyperbolic tendencies. 


\section{MELBOURNE ASIA REVIEW}

July 13, 2020

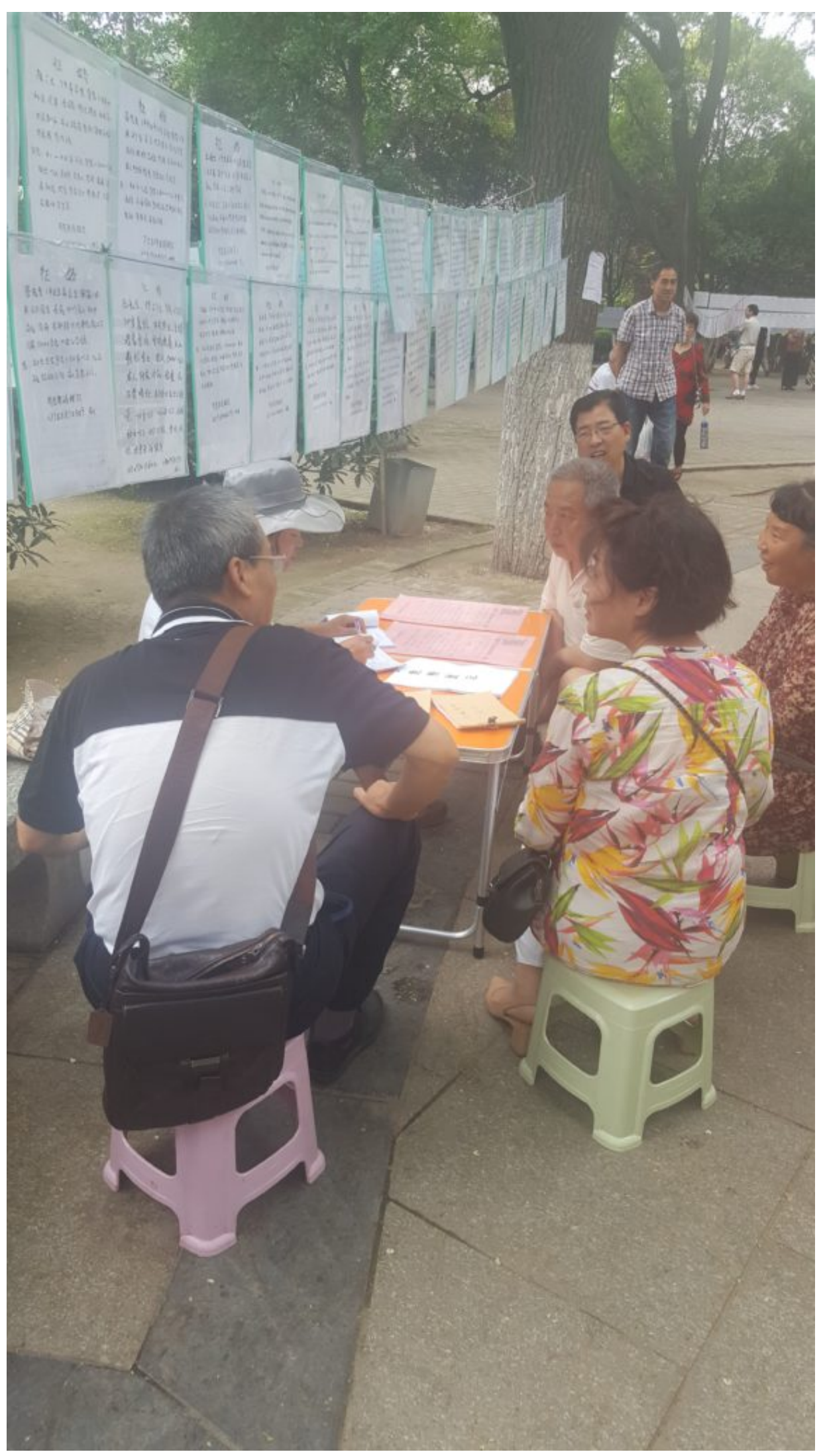


The emotional release that matchmaking corners provide helps soothe the gaping contradiction in the parents' hierarchies of social acceptability. Rising divorce rates highlights the reality that marriage is not so stable, however the ongoing disdain for divorcees confronts the fact that their children are now in that category or might find themselves in that category in the future. Changing gender relations further complicate this picture of marriage as parents struggle to understand the contemporary desires of younger folk. Indeed, as an outlet for the emotional needs of parents, and also a collective debate, the matchmaking corner is a place for the older generation to manage the social and psychological contradictions that confront many parents in China today.

Images: Matchmaking corner Xi'an, 2019. Credit: Author. 